\title{
Metabolic changes in an animal model of amyotrophic lateral sclerosis evaluated by $\left[{ }^{18} \mathrm{~F}\right]$-FDG positron emission tomography
}

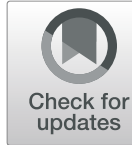

\author{
Bruno Lima Giacobbo, Tomás Mediavilla, Daniel J. Marcellino and Fahad Sultan * (D)
}

\section{Main text}

Energy metabolism has been proposed to be affected in amyotrophic lateral sclerosis (ALS), due to its relationship with SOD1 ${ }^{\text {G93A }}$-dependent mitochondrial loss-offunction $[1,2]$. Although the metabolic state and the use of its dysfunction as an early diagnostic criterion have been evaluated in ALS patients by positron emission tomography (PET), preclinical research in animal models is rare. In this study, we imaged glucose metabolism using $\left[{ }^{18} \mathrm{~F}\right]$-fluorodeoxyglucose (FDG) (NanoScan PET/CT, Mediso Medical Imaging Systems, Hungary) in both male and female mice expressing a mutated human SOD1 variant $\left(\mathrm{hSOD} 1^{\mathrm{G} 93 \mathrm{~A}}\right.$ ) with ALS-like symptoms, and compared these animals to age- and sex-matched littermate controls $\left(\mathrm{SOD} 1^{\mathrm{WT}}\right)$.

Generalized Linear Models analysis (Supplemental Methods) showed significant between-group differences in body weight at the time of scan $(F=28.81 ; P<0.0001)$, with post-hoc comparisons indicating that the male WT mice weighed significantly higher than all other groups, while the female ALS mice weighed significantly lower when compared with all other groups (Table S1). There were no significant differences in the age or the injected dose administered at the time of scan (all $P>0.05$ ). The $\left[{ }^{18} \mathrm{~F}\right]$-FDG uptake showed a marked difference between WT and ALS mice (Fig. 1). There was a lower uptake of $\left[{ }^{18} \mathrm{~F}\right]$-FDG in the brains of ALS mice compared to the WT littermates. A detailed statistical analysis of standardized uptake value (SUV)-normalized $\left[{ }^{18} \mathrm{~F}\right]$-FDG uptake using a Generalized Estimating Equations approach revealed a significant effect of sex for almost all regions evaluated (Table S2), with female mice showing a higher SUV for all

\footnotetext{
* Correspondence: fahad.sultan@umu.se
}

Department of Integrative Medical Biology, Umeå University, Umeå, Sweden regions assessed (main effect of sex: Wald- $\chi^{2}<0.0001$ ) except the cerebellum, basal forebrain and amygdala that showed no significant sex difference. We observed a significant effect of genotype on the $\left[{ }^{18} \mathrm{~F}\right]$-FDG SUV uptake (main effect of genotype: Wald- $\chi^{2}<0.0001$ ) with significantly lower SUV uptake in the hippocampus, thalamus, midbrain, and right inferior colliculus in SOD ${ }^{\text {G93A }}$ than in the WT animals. In general, there was a significant interaction effect between sex and genotype (sex $\times$ genotype interaction: Wald- $\left.\chi^{2}<0.0001\right)$. Pairwise comparisons revealed significant differences between WT females and SOD1 $1^{\mathrm{G} 93 \mathrm{~A}}$ males in the left hippocampus $(P<0.0001)$ and the left midbrain $(P=0.049)$.

Due to a possible influence of body weight between ALS and WT mice, $\left[{ }^{18} \mathrm{~F}\right]$-FDG uptake from each volume of influence (VOI) was normalized to the average uptake of the whole brain for each individual, to eliminate any possible effect of body weight. The tissue-to-reference ratio (TRR) analysis showed that the sex differences found in SUV disappeared except in the right striatum. Regarding the main effect of genotype, there were significant differences between the WT and SOD $1^{\mathrm{G} 93 \mathrm{~A}}$ animals in the hippocampus, thalamus, basal forebrain, olfactory bulb, right amygdala, midbrain, and right inferior colliculus (Table S3).

In this study, we found significant changes in glucose metabolism in the brains of SOD $1^{\mathrm{G} 93 \mathrm{~A}}$ animals when compared with WT control littermates, indicating a change in metabolic pattern in these animals. To specifically investigate early changes in the central nervous system, we scanned animals that were at an initial stage of disease, stage 1 [3].

The effects of ALS on metabolic function in humans and animal models of ALS are yet to be fully understood. In animals, one study has measured the glucose

\section{$\triangle B M C$}

(c) The Author(s). 2021 Open Access This article is licensed under a Creative Commons Attribution 4.0 International License, which permits use, sharing, adaptation, distribution and reproduction in any medium or format, as long as you give appropriate credit to the original author(s) and the source, provide a link to the Creative Commons licence, and indicate if changes were made. The images or other third party material in this article are included in the article's Creative Commons licence, unless indicated otherwise in a credit line to the material. If material is not included in the article's Creative Commons licence and your intended use is not permitted by statutory regulation or exceeds the permitted use, you will need to obtain permission directly from the copyright holder. To view a copy of this licence, visit http://creativecommons.org/licenses/by/4.0/ The Creative Commons Public Domain Dedication waiver (http://creativecommons.org/publicdomain/zero/1.0/) applies to the data made available in this article, unless otherwise stated in a credit line to the data. 


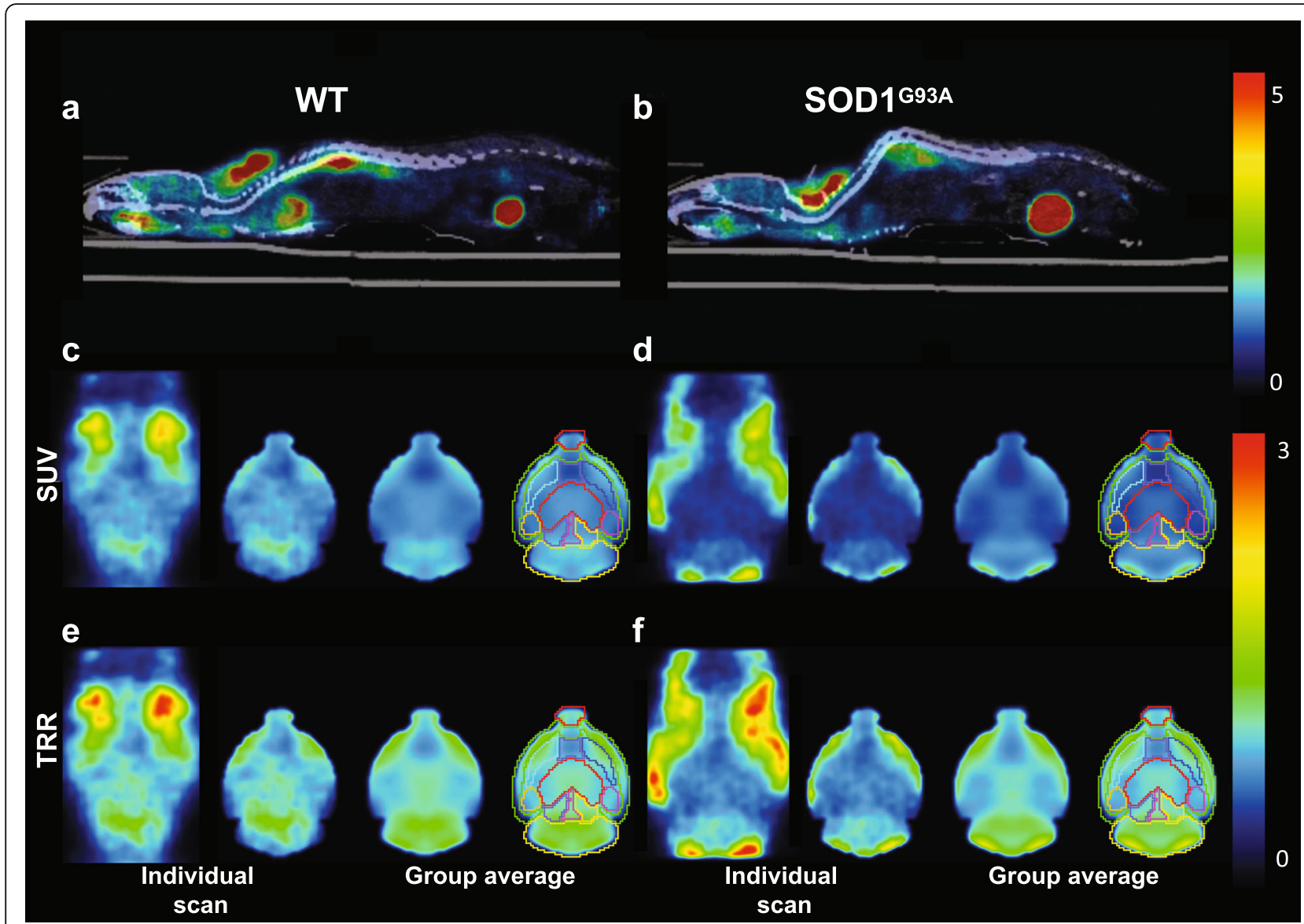

Fig. 1 a, b: Representative images of whole-body $\left[{ }^{18} \mathrm{~F}\right]-\mathrm{FDG}$ at the sagittal plane in a WT (a) and an ALS animal (b). Color scale bar indicates radiotracer uptake value normalized for injected dose and weight (SUV). c, d: Horizontal plane of the head in cropped SUV images. From left to right: an individual head-cropped image; an individual brain-masked image; group-based average image; and volume of influence (VOI) placement for data analysis. Color scale bar indicates radiotracer uptake normalized for injected dose and weight (SUV). e, f: Horizontal plane of the head with radioactivity normalized to the average radioactivity in the whole brain (TRR). From left to right: an individual head-cropped image; an individual brain-masked image; group-based average image; and VOI placement for data analysis. Color scale bar indicates radiotracer uptake normalized for averaged radioactivity in the whole brain

uptake in the brains of mice carrying the human TDP$43^{\mathrm{A} 315 \mathrm{~T}}$ mutation [4]. The authors observed a significant hypometabolism in motor and somatosensory cortex, as well as a hypermetabolism in amygdala and brainstem. In humans, however, brain metabolism in ALS patients with $\left[{ }^{18} \mathrm{~F}\right]$-FDG PET has been studied with a focus on prediction of ALS onset and characterization of disease progression, both with mixed results [5]. In humans, PET $\left[{ }^{18} \mathrm{~F}\right]$-FDG studies have reported a widespread change in brain glucose uptake. Some of these studies have pointed towards a decrease in $\left[{ }^{18} \mathrm{~F}\right]$ - FDG PET uptake in primary motor and other premotor regions, while also showing hypermetabolic regions such as the limbic system, brainstem and cerebellum, irrespective of the ALS onset type (i.e. bulbar- or spinal-onset ALS) [6]. The hypometabolism in frontal regions has been explained with the "dying forward" hypothesis of ALS [7] leading to a reduction in glutamatergic cortico-cortical neurotransmission, which has a major effect on glucose consumption. Our observation of early reductions in glucose uptake suggests that hypometabolism can also occur prior to such changes in neurotransmission and can be due to an overall hypometabolic state in ALS.

Hypometabolism has also been described in other brain regions in humans, such as in the thalamus [5]. Consistently, we found a $12 \%$ decrease in thalamic $\left[{ }^{18} \mathrm{~F}\right]$-FDG PET uptake normalized to the whole brain. Interestingly, these changes in thalamic glucose uptake appear to be specific for familial ALS as recently proposed in a study of carriers of C9orf72 gene [8]. However, it is not entirely clear whether specific thalamic nuclei play a key role in the onset of ALS, or whether the hypometabolism of thalamus is associated with overall reductions in the relay of motor and sensory information throughout the brain. 
Further, we observed bilateral decreases of metabolic activity in hippocampus and midbrain in SOD1 ${ }^{\text {G93A }}$ mice, in both SUV and TRR (Tables S2 and S3). Interestingly, human data predominantly report a hypermetabolic state in hippocampus and midbrain, either by PET or through the use of additional in vivo techniques [8]. An explanation for such increased metabolism in these areas is an increase of reactive gliosis from oxidative stress and neurotoxicity. Structural MRI data, on the other hand, suggest a relative decrease in hippocampal volume in ALS patients and loss of hippocampusdependent cognitive functions [9], with similar atrophy observed in midbrain. This atrophy in the midbrain and hippocampus has also been observed in $\mathrm{SOD}^{\mathrm{G}}{ }^{\mathrm{93A}}$ animals. Thus, it is possible that this increased atrophy in the midbrain is also related to a decreased glucose metabolism resulting from neuronal loss of function and neurodegeneration. In fact, a study has reported increased gliosis in hippocampus and brainstem of $\mathrm{SOD} 1{ }^{\mathrm{G} 93 \mathrm{~A}}$ rats prior to the development of ALS-like symptomatology [10], suggesting that the hypermetabolic state of hippocampus might occur at earlier stages of disease, and then decline over time to a hypometabolic state as disease progresses. In the future, longitudinal scans including those at a prodromal stage and at several time points later in ALS animal models are needed to test this hypothesis.

\section{Abbreviations}

ALS: Amyotrophic lateral sclerosis; $\left[{ }^{18} \mathrm{~F}\right]-\mathrm{FDG}$ : $\left[{ }^{18} \mathrm{~F}\right]$-fluorodeoxyglucose; PET: Positron emission tomography; SUV: Standardized uptake values; TRR: Tissue to reference ratio; VOI: Volume of influence

\section{Supplementary Information}

The online version contains supplementary material available at https://doi. org/10.1186/s40035-021-00246-1.

Additional file 1: Supplementary methods. Detailed description of material and methods.

Additional file 2: Supplementary tables: Table S1. Animal weight, radioactivity measurements and animal age at the time of scan. Table S2. Main effects and interaction of sex and genotype in [F]-FDG SUV uptake. Table S3. Main effects and interaction of sex and genotype in $\left[{ }^{18} \mathrm{~F}\right]-\mathrm{FDG}$ activity normalized to the Whole Brain (TRR).
Funding

BG was funded by a Kempestiftelserna grant to DM and FS. This study was also supported by the Department of Integrative Medical Biology, Umeå University (DM and FS) and from Umeå University Medical Faculty (DM). Open Access funding provided by Umea University.

Availability of data and materials

The datasets used during the current study are available from the corresponding author on reasonable request.

\section{Declarations}

Ethics approval and consent to participate

All experimental procedures were conducted in accordance with the Umeå University's animal ethical committee (Ethical permit number: 5.2.18-19236/17).

\section{Consent for publication}

Not applicable.

\section{Competing interests}

The authors declare that they have no competing interests.

Received: 15 March 2021 Accepted: 10 June 2021

Published online: 23 June 2021

\section{References}

1. Gurney ME, Pu H, Chiu AY, Dal Canto MC, Polchow CY, Alexander DD, et al. Motor neuron degeneration in mice that express a human $\mathrm{Cu}, \mathrm{Zn}$ superoxide dismutase mutation. Science. 1994;264(5166):1772-5.

2. Hardiman O, Al-Chalabi A, Chio A, Corr EM, Logroscino G, Robberecht W, et al. Amyotrophic lateral sclerosis. Nat Rev Dis Primers. 2017;3(1):17071.

3. Hatzipetros T, Kidd JD, Moreno AJ, Thompson K, Gill A, Vieira FG. A quick phenotypic neurological scoring system for evaluating disease progression in the SOD1-G93A mouse model of ALS. J Vis Exp. 2015;104.

4. Weerasekera A, Crabbe M, Tome SO, Gsell W, Sima D, Casteels C, et al. Noninvasive characterization of amyotrophic lateral sclerosis in a hTDP43(A315T) mouse model: a PET-MR study. Neuroimage Clin. 2020;27:102327.

5. Van Laere K, Vanhee A, Verschueren J, De Coster L, Driesen A, Dupont P, et al. Value of 18 fluorodeoxyglucose-positron-emission tomography in amyotrophic lateral sclerosis: a prospective study. JAMA Neurol. 2014;71(5): 553-61.

6. Dodge JC, Treleaven CM, Fidler JA, Tamsett TJ, Bao C, Searles M, et al. Metabolic signatures of amyotrophic lateral sclerosis reveal insights into disease pathogenesis. Proc Natl Acad Sci U S A. 2013;110(26):10812-7.

7. Baker MR. ALS—dying forward, backward or outward? Nat Rev Neurol. 2014; 10(11):660.

8. Cistaro A, Pagani M, Montuschi A, Calvo A, Moglia C, Canosa A, et al. The metabolic signature of C9ORF72-related ALS: FDG PET comparison with nonmutated patients. Eur J Nucl Med Mol Imaging. 2014;41(5):844-52.

9. Vandoorne T, De Bock K, Van Den Bosch L. Energy metabolism in ALS: an underappreciated opportunity? Acta Neuropathol. 2018;135(4):489-509.

10. Stamenkovic S, Ducic T, Stamenkovic V, Kranz A, Andjus PR. Imaging of glial cell morphology, SOD1 distribution and elemental composition in the brainstem and hippocampus of the ALS hSOD1(G93A) rat. Neuroscience.

\section{Acknowledgements \\ The authors would like to acknowledge Thomas Brännström for providing the initial ALS SOD $1^{\text {G93A }}$ breeding pairs to establish a cohort for performing this study. The authors would also like to acknowledge the support from Madelene Ericsson and Jan Axelsson on the development of the PET protocol, as well as the support in data analysis. Lastly, the authors would like to acknowledge the Small Animal Research and Imaging Facility at Umeå University for providing the equipment and technical support for performing the study.}

\section{Authors' contributions}

BG designed the study, collected, and analyzed the data, and prepared the manuscript. TM participated in data collection and preparation of the manuscript. DM and FS participated in study design and preparation of the manuscript. The author(s) read and approved the final manuscript.

\section{7;357:37-55.}

Ready to submit your research? Choose BMC and benefit from:

- fast, convenient online submission

- thorough peer review by experienced researchers in your field

- rapid publication on acceptance

- support for research data, including large and complex data types

- gold Open Access which fosters wider collaboration and increased citations

- maximum visibility for your research: over $100 \mathrm{M}$ website views per year

At BMC, research is always in progress.

Learn more biomedcentral.com/submissions 